Article

\title{
A Voltammetric Sensor Based on Chemically Reduced Graphene Oxide-Modified Screen-Printed Carbon Electrode for the Simultaneous Analysis of Uric Acid, Ascorbic Acid and Dopamine
}

\author{
Prosper Kanyong *, Sean Rawlinson and James Davis \\ School of Engineering, Ulster University, Jordanstown BT37 0QB, United Kingdom; \\ Rawlinson-S@email.ulster.ac.uk (S.R.); james.davis@ulster.ac.uk (J.D.) \\ * Correspondence: p.kanyong@ulster.ac.uk; Tel.: +44-28-9036-8663 \\ Academic Editor: Igor Medintz \\ Received: 28 November 2016; Accepted: 17 December 2016; Published: 20 December 2016
}

\begin{abstract}
A disposable screen-printed carbon electrode (SPCE) modified with chemically reduced graphene oxide (rGO) (rGO-SPCE) is described. The rGO-SPCE was characterized by UV-Vis and electrochemical impedance spectroscopy, and cyclic voltammetry. The electrode displays excellent electrocatalytic activity towards uric acid (UA), ascorbic acid (AA) and dopamine (DA). Three resolved voltammetric peaks (at $183 \mathrm{mV}$ for UA, $273 \mathrm{mV}$ for AA and $317 \mathrm{mV}$ for DA, all vs. $\mathrm{Ag} / \mathrm{AgCl}$ ) were found. Differential pulse voltammetry was used to simultaneously detect UA, $\mathrm{AA}$ and DA in their ternary mixtures. The linear working range extends from 10 to $3000 \mu \mathrm{M}$ for UA; 0.1 to $2.5 \mu \mathrm{M}$, and 5.0 to $2 \times 10^{4} \mu \mathrm{M}$ for $\mathrm{AA}$; and 0.2 to $80.0 \mu \mathrm{M}$ and 120.0 to $500 \mu \mathrm{M}$ for DA, and the limits of detection $(\mathrm{S} / \mathrm{N}=3)$ are $0.1,50.0$, and $0.4 \mu \mathrm{M}$, respectively. The performance of the sensor was evaluated by analysing spiked human urine samples, and the recoveries were found to be well over $98.0 \%$ for the three compounds. These results indicate that the rGO-SPCE represents a sensitive analytical sensing tool for simultaneous analysis of UA, AA and DA.
\end{abstract}

Keywords: multiplex sensing; graphene-based electrodes; differential pulse voltammetry; electrochemical impedance spectroscopy; UV-Vis spectroscopy; screen-printed electrodes

\section{Introduction}

Uric acid (UA) is a principal end product of purine metabolism [1] and abnormal levels in urine and/or blood are symptomatic of diseases such as Lesch-Nyhan syndrome, gout and hyperuricemia, and renal and cardiovascular diseases [2]. Ascorbic acid (AA) is a water-soluble vitamin that has antioxidant properties and can be found in high concentrations in some plant foods [3]. AA is involved in many biological processes including improving immunity, cancer prevention, treating common cold, scurvy and mental illness, and free radical scavenging [4]. Dopamine (DA) is an essential neurotransmitter that forms part of the family of catecholamines. It plays vital roles in the normal functions of the renal, metabolic, hormonal, cardiovascular and central nervous systems $[5,6]$. High levels of DA in human bodily fluids have been found to be associated with several neurological disorders including Huntington's disease, restless legs syndrome, schizophrenia, attention deficit hyperactivity disorder and Parkinson's disease [7,8].

Several analytical methods such as high performance liquid chromatography, chemiluminescence, UV-Vis spectroscopy, capillary electrophoresis and electroanalytical methods [9-11] have been developed for the detection of these compounds. Owing to the electroactive nature of UA, AA and DA, and their coexistence in human bodily fluids such as urine, electrochemical method is considered most attractive for their simultaneous analysis because they are rapid, low-cost and sensitive. 
However, the main drawbacks associated with the use of traditional electrode materials for their simultaneous analysis are low reproducibility due to electrode fouling and poor selectivity arising from overlapping voltammetric peaks [12]. Electrodes modified with nanoparticles [13], ionic liquids [14], redox mediators [15], polymers and polymer composites [16], metal oxides [17], and carbon black, carbon nanotubes or fullerene [18] have been useful in solving these problems. However, there are still some drawbacks with regards to electrode complexity and inactivation, as well as stability of electrode modifiers/particles; thus, it is important to find suitable electrode materials that permit their selective determination.

In this study, reduced graphene oxide (rGO) was prepared through mild treatment of graphene oxide (GO) with sodium borohydride $\left(\mathrm{NaBH}_{4}\right)$. The rGO dispersion then was casted onto the working area of an in-house fabricated screen-printed carbon electrode (SPCE) to form rGO-SPCE. The electrochemical behaviour of UA, AA and DA at rGO-SPCE was thoroughly investigated. The sensor was subsequently employed for the simultaneous analysis of the compounds in ternary mixtures in buffer. Details of the sensor fabrication, characterization and application to the analysis of the compounds are described and discussed.

\section{Experimental}

\subsection{Apparatus and Reagents}

Electrochemical experiments were conducted using VSP-300 Multichannel Potentiostat/Galvanostat/EIS (Bio-Logic Science Instruments, Seyssinet-Pariset, France) with a standard three-electrode configuration. Impedance measurements in $\mathrm{K}_{4}\left[\mathrm{Fe}(\mathrm{CN})_{6}\right]$ was carried out at open circuit from frequency range of $200 \mathrm{kHz}$ to $0.1 \mathrm{~Hz}$. Under the optimized conditions, unless otherwise stated, DPVs were recorded with pulse amplitude of $50 \mathrm{mV}$, pulse time of $0.05 \mathrm{~s}$, voltage step time of $0.5 \mathrm{~s}$, voltage step of $5 \mathrm{mV}$ and at $50 \mathrm{mV} \cdot \mathrm{s}^{-1} \mathrm{scan}$ rate. UV-Vis spectra were recorded using Jenway 6715 UV-Vis (Multi-cell changer) spectrophotometer (Bibby Scientific Ltd., Stone, UK). An $\mathrm{Ag} / \mathrm{AgCl}(1.0 \mathrm{M} \mathrm{KCl}), \mathrm{SPCE}$ or rGO-SPCE and a platinum wire were used as the reference, working and counter electrodes. Ascorbic acid and uric acid were purchased from Alfa Aesar, Heysham, UK. Graphene oxide (GO), dopamine hydrochloride, methanol, $\mathrm{NaOH}$, $\mathrm{NaBH}_{4}$ and sodium carbonate $\left(\mathrm{Na}_{2} \mathrm{CO}_{3}\right)$ were purchased from Sigma Aldrich, Irvine, UK. Urine samples were obtained from the authors and informed consent was obtained.

\subsection{Preparation of $r G O$}

The chemical reduction of GO was per the method reported by Chua and Pumera [19] with some modification. Briefly, to a dispersion of graphene oxide $(6.0 \mathrm{mg})$ in methanol $(2.5 \mathrm{~mL})$ was added $\mathrm{Na}_{2} \mathrm{CO}_{3}(5.0 \mathrm{mM})$ to adjust the $\mathrm{pH}$ to $\sim 8.5$. Sodium borohydride $\left(\mathrm{NaBH}_{4}, 28.4 \mathrm{mg}\right)$ was then added into the resultant dispersion and stirred at $70^{\circ} \mathrm{C}$ with refluxing for $5 \mathrm{hr}$. Upon completion, the mixture was repeatedly centrifuged (at $400 \mathrm{rpm}, 15 \mathrm{~min}$ ) and washed with methanol and water until a neutral $\mathrm{pH}$ of the filtrate was obtained. The filtrate (reduced graphene oxide, $\mathrm{rGO}$ ) was then re-suspended in $2.0 \mathrm{~mL}$ of distilled water.

\subsection{Fabrication of SPCE and $r G O-S P C E$}

The fabrication of the unmodified SPCE transducer was prepared as previously described [20,21]. Briefly, the base unmodified SPCE transducer was printed onto a Valox substrate using DEK 240 Manual Screen Printing Machine, Stainless Steel Screen Mesh and graphite ink (GEM Product code: C205010697) and cured at $70{ }^{\circ} \mathrm{C}$ for $90 \mathrm{~min}$. A polymeric dielectric material (GEM Product code: D2071120P1) was then screen-printed onto the cured SPCE to define the working area. Thereafter, $2.0 \mu \mathrm{L}$ of rGO suspension in water was dropped onto the working area of the SPCE and allowed to air-dry in room temperature to form rGO-SPCE (Scheme 1). The rGO-SPCE was rinsed in distilled water to remove any unbound $\mathrm{rGO}$ and dried in $\mathrm{N}_{2}$. 
(A) Screen-printed carbon electrode (SPCE)

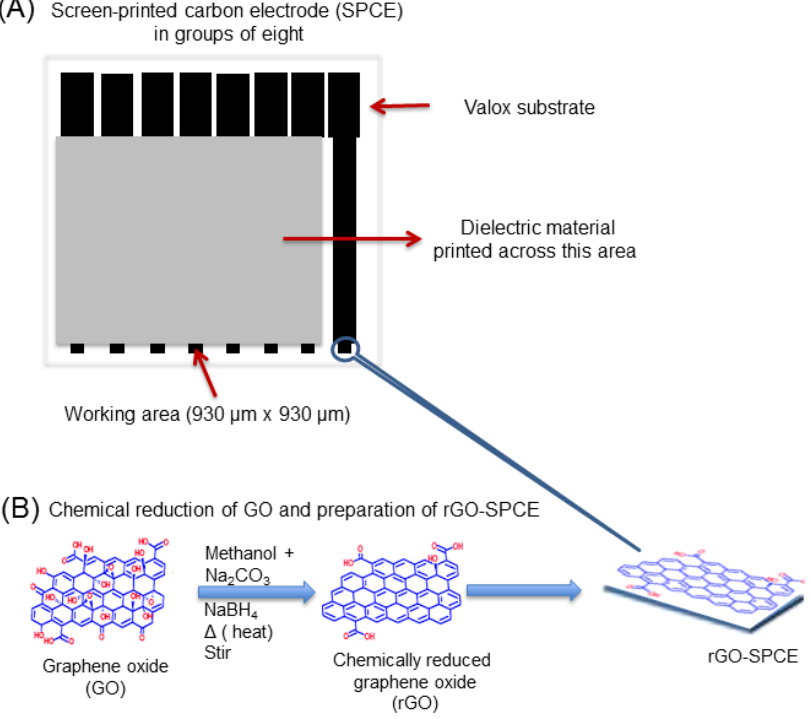

Scheme 1. (A) Screen-printing of carbon electrodes; and (B) chemical reduction of graphene oxide and modification of SPCE.

\section{Results and Discussion}

\subsection{Characterization of $r G O-S P C E$}

Both graphene oxide (GO) and reduced graphene oxide ( $\mathrm{rGO}$ ) possess unique set of electrical and optical properties that is different from pristine graphene because of the structural changes arising from the presence of oxygen functionalities within $\mathrm{sp}^{2}$ bonded carbon networks $[17,22]$. Analyses of GO and rGO were performed using UV-Vis spectroscopy (Figure 1A). The GO spectrum exhibits a characteristic absorption peak at $235 \mathrm{~nm}$ corresponding to the $\pi \rightarrow \pi^{*}$ transition of the aromatic $\mathrm{C}=\mathrm{C}$ bonds [22]. After chemical reduction with $\mathrm{NaHB}_{4}$, this peak shifts from $254 \mathrm{~nm}$ to $282 \mathrm{~nm}$, and the intensity of absorption in the spectra region increased, indicating that the conjugated $\mathrm{C}=\mathrm{C}$ bonds were restored by reduction [23]; thus, giving evidence that the GO has been reduced.
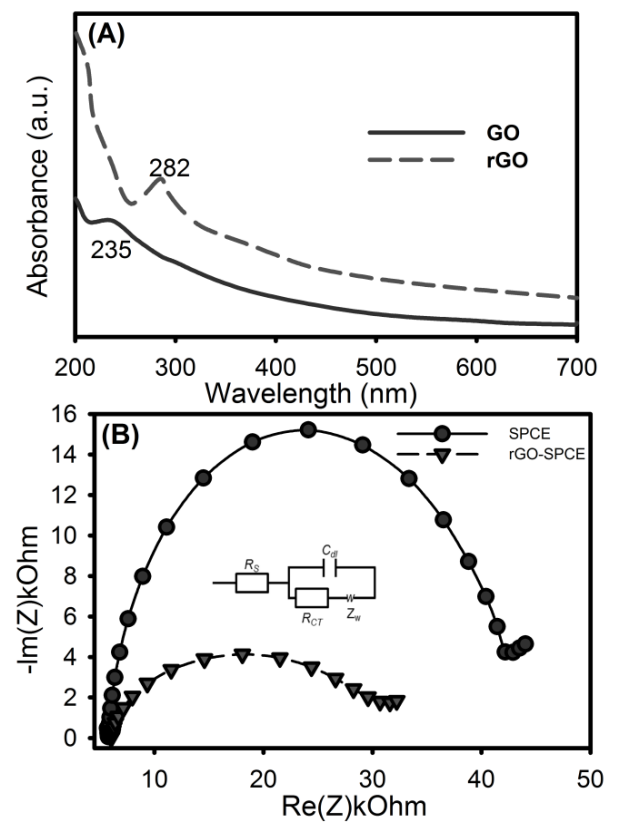

Figure 1. Cont. 


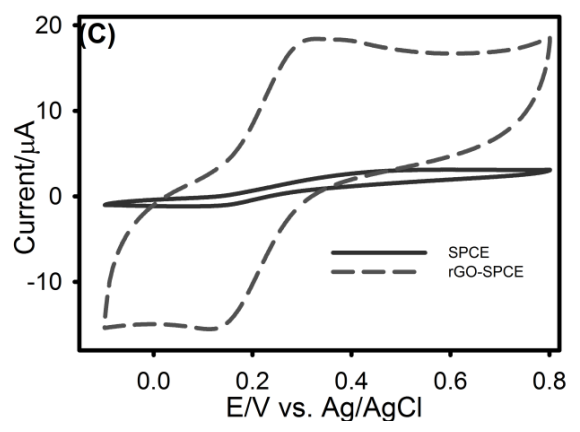

Figure 1. (A) UV-Vis spectra of GO and rGO suspensions in water. (B) Nyquist plots observed for impedance measurements at SPCE and rGO-SPCE in Britton-Robinson (BR) buffer ( $\mathrm{pH} 7.0$ ) containing $5.0 \mathrm{mM} \mathrm{K}_{4}\left[\mathrm{Fe}(\mathrm{CN})_{6}\right]$ and $0.1 \mathrm{M} \mathrm{KCl}$. Insert: Randles equivalent circuit used for data fitting, $\mathrm{R}_{\mathrm{S}}$, resistance of the electrolyte solution; $\mathrm{R}_{\mathrm{CT}}$, electron-transfer resistance; $\mathrm{Z}_{\mathrm{W}}$, Warburg impedance; $\mathrm{C}_{\mathrm{dl}}$, double layer capacitance. (C) Cyclic voltammograms of $5.0 \mathrm{mM} \mathrm{K}_{4}\left[\mathrm{Fe}(\mathrm{CN})_{6}\right]$ in BR buffer (pH 7.0) containing $0.1 \mathrm{M} \mathrm{KCl}$ at SPCE and rGO-SPCE, $50.0 \mathrm{mV} \cdot \mathrm{s}^{-1}$ scan rate.

The electrochemical properties of SPCE and rGO-SPCE were examined using electrochemical impedance spectroscopy (EIS) and cyclic voltammetry. EIS is a versatile and sensitive technique for studying charge transfer processes occurring at electrode surfaces [24]. Figure 1B illustrates experimental Nyquist spectra recorded in $\mathrm{K}_{4}\left[\mathrm{Fe}(\mathrm{CN})_{6}\right]$ solution using SPCE and rGO-SPCE including the equivalent Randles circuit used to extract the impedance circuit fitted data in Table 1. According to the Randles circuit, a semi-circle located at the higher frequency region, corresponds to the charge transfer resistance $\left(\mathrm{R}_{\mathrm{CT}}\right)$ of the electrode material. The SPCE showed $\mathrm{R}_{\mathrm{CT}}$ value of $\sim 16 \mathrm{k} \Omega$ while rGO-SPCE had a reduced $R_{C T}$ value of $\sim 5.0 \mathrm{k} \Omega$. This shows that the charge transfer rate for $\left[\mathrm{Fe}(\mathrm{CN})_{6}\right]^{3-} /\left[\mathrm{Fe}(\mathrm{CN})_{6}\right]^{4-}$ redox process increased upon employing rGO. From the obtained data (Table 1), it can be concluded that rGO-SPCE have higher electrocatalytic activity in comparison with the bare SPCE.

Table 1. Impedance circuit fitted parameters for SPCE and rGO-SPCE.

\begin{tabular}{ccc}
\hline Parameter & SPCE & rGO-SPCE \\
\hline $\operatorname{Rs}_{(}(\Omega)$ & 2998 & 2997 \\
$\mathrm{C}_{\mathrm{dl}}(\mu \mathrm{F})$ & 1.4986 & 7.071 \\
$\mathrm{R}_{\mathrm{CT}}(\Omega)$ & 16049 & 5004 \\
$\mathrm{Z}_{\mathrm{W}}\left(\Omega \cdot \mathrm{s}^{-1 / 2}\right)$ & 2181 & 1983 \\
\hline
\end{tabular}

Cyclic voltammetry $(\mathrm{CV})$ was also carried out as an independent method to verify the findings of the EIS. Figure $1 \mathrm{C}$ shows $\mathrm{CVs}$ of $\mathrm{K}_{4}\left[\mathrm{Fe}(\mathrm{CN})_{6}\right]$ at SPCE and rGO-SPCE. In comparison to what occurred at SPCE, rGO-SPCE did not only exhibit well-defined redox peaks but also exhibited a characteristic increase of the anodic and cathodic peaks for $\left[\mathrm{Fe}(\mathrm{CN})_{6}\right]^{3-} /\left[\mathrm{Fe}(\mathrm{CN})_{6}\right]^{4-}$ redox couple. Higher peak currents and a smaller peak-to-peak potential separation $\left(\Delta E_{\mathrm{p}}\right)$ at rGO-SPCE $\left(I_{\mathrm{pa}}=18.5 \mu \mathrm{A}, I_{\mathrm{pc}}=14.8 \mu \mathrm{A} ; \Delta E_{\mathrm{p}}=\sim 140.0 \mathrm{mV}\right)$ when compared with $\operatorname{SPCE}\left(I_{\mathrm{pa}}=2.9 \mu \mathrm{A}, I_{\mathrm{pc}}=1.1 \mu \mathrm{A}\right.$; $\Delta E_{\mathrm{p}}=\sim 500 \mathrm{mV}$ ) were observed. There were also slight shifts in both the anodic and cathodic peak potentials to less positive values, giving rise to a smaller peak-to-peak separation $\left(\Delta E_{\mathrm{p}}=140.0 \mathrm{mV}\right)$. This enhancement in electrocatalytic activity can be attributed to the electrocatalytic effect of rGO. Thus, the analysed CV data are in agreement with the results obtained from EIS and provides further evidence of the reduction of GO.

\subsection{Cyclic Voltammetric Analysis of $U A, A A$ and $D A$ at SPCE and $r G O-S P C E$}

Typical CVs recorded for a ternary mixture of UA, AA and DA at SPCE and rGO-SPCE in Britton-Robinson (BR) buffer (pH 7.0) are depicted in Figure 2. In Figure 2A, UA and AA exhibit broad 
irreversible oxidation peaks at $0.135 \mathrm{~V}$ and $0.295 \mathrm{~V}$ on SPCE, respectively, while DA has an anodic peak and a broadened cathodic peak at $0.295 \mathrm{~V}$ and $0.050 \mathrm{~V}\left(\Delta E_{\mathrm{p}}=\sim 245 \mathrm{mV}\right)$, respectively. This is an indication of a sluggish electron transfer process, which can be attributed to the conductivity of the SPCE material and/or electrode fouling caused by the deposition of the compounds including their redox products on the electrode. The oxidation peaks for AA and DA overlaps; thus, the oxidation peaks associated with the compounds could not be resolved. However, at rGO-SPCE, the oxidation peaks for UA, AA and DA are resolved at $\sim 0.112 \mathrm{~V}, \sim 0.18 \mathrm{~V}$ and $0.287 \mathrm{~V}$, respectively. The oxidation peak for DA (at $\sim 0.287 \mathrm{~V}$ ) formed a quasi-reversible couple at $\sim 0.101 \mathrm{~V}$. This anodic peak can be attributed to the oxidation of DA to $o$-dopaminequinone while the cathodic peak can be attributed to the reduction of the $o$-dopaminequinone back to DA as has been previously reported [25]. The smaller $\Delta E_{\mathrm{p}}$ value of $186 \mathrm{mV}$ (when compared with $245 \mathrm{mV}$ at SPCE) for DA suggests that the reversibility of DA at rGO-SPCE is remarkably improved; thus, enabling the simultaneous analysis of the three compounds.
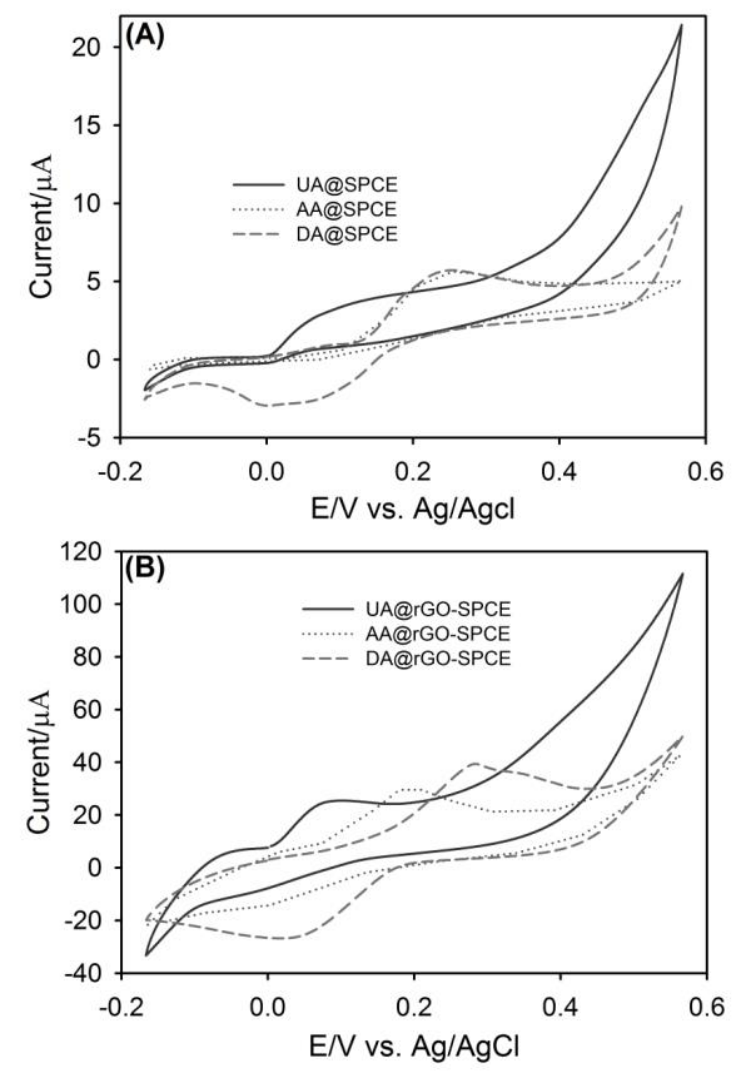

Figure 2. Cyclic voltammograms of ternary mixtures of UA $(0.5 \mathrm{mM}), \mathrm{AA}(5.0 \mathrm{mM})$ and DA $(0.5 \mathrm{mM})$ in BR buffer ( $\mathrm{pH} 7.0$ ) at: (A) SPCE; and (B) rGO-SPCE. Scan rate, $50 \mathrm{mV} \cdot \mathrm{s}^{-1}$.

\subsection{The Effect of Scan Rate on Voltammetric Behavior of UA, AA and DA at rGO-SPCE}

The kinetics of the electrode reaction was further investigated by evaluating the effect of scan rate (v) on the anodic peak currents $\left(I_{\mathrm{pa}}\right)$. As shown in Figure 3, increasing scan rate increases the $I_{\mathrm{pa}}$ of UA, AA and DA linearly with slight positive shifts in the oxidation peak potentials $\left(E_{\mathrm{pa}}\right)$, suggesting that adsorption of the compounds on rGO-SPCE does not occur. Plots of $I_{\mathrm{pa}}$ vs. square root of scan rate $(\sqrt{ } v)$ (shown as inserts in Figure 3) resulted in the following linear equations: UA, $I_{\mathrm{pa}}(\mu \mathrm{A})=8.99 v^{1 / 2}$ $\left(\mathrm{mV} \cdot \mathrm{s}^{-1}\right)-30.89, \mathrm{R}^{2}=0.994 ; \mathrm{AA}, I_{\mathrm{pa}}(\mu \mathrm{A})=10.59 v^{1 / 2}\left(\mathrm{mV} \cdot \mathrm{s}^{-1}\right)-39.41, \mathrm{R}^{2}=0.977$; and DA, $I_{\mathrm{pa}}(\mu \mathrm{A})=12.38 v^{1 / 2}\left(\mathrm{mV} \cdot \mathrm{s}^{-1}\right)-40.88, \mathrm{R}^{2}=0.999$. These suggest a diffusion-controlled process. 

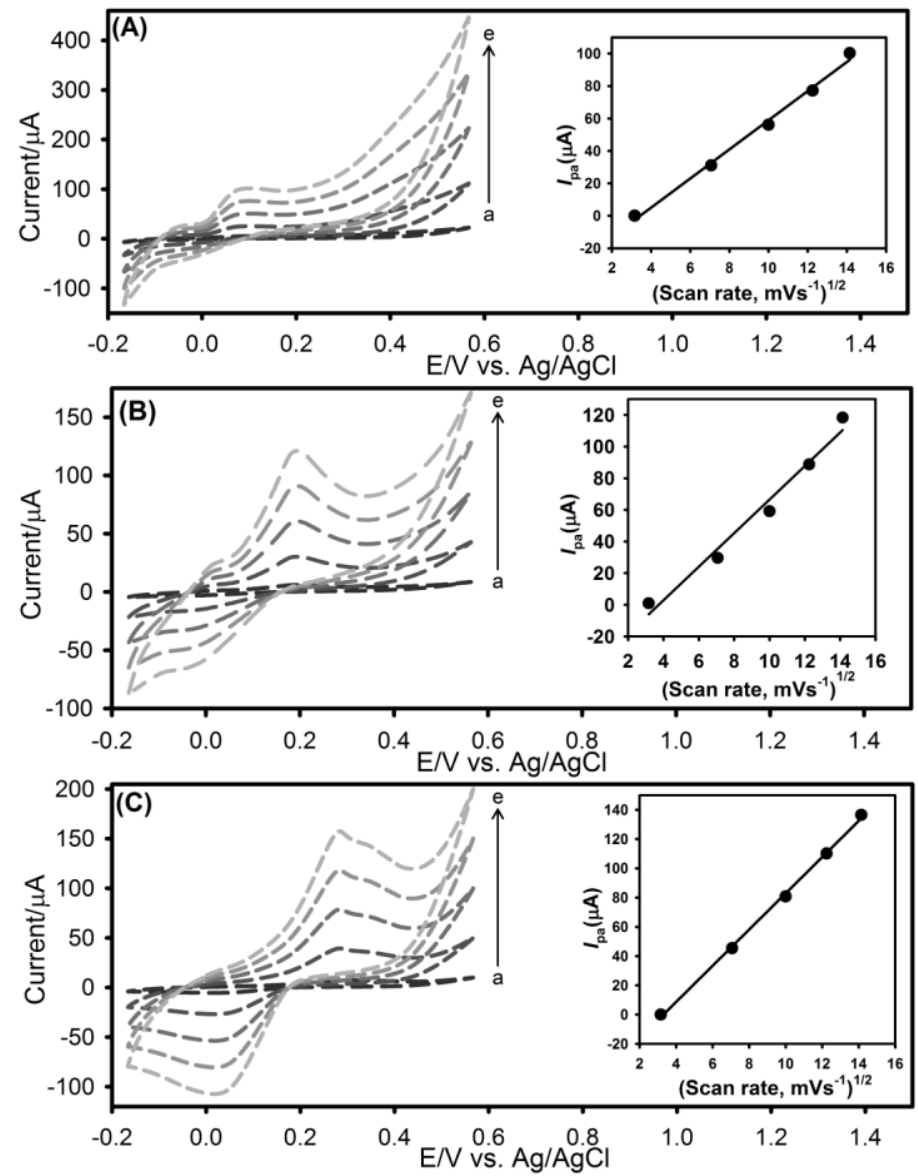

Figure 3. Cyclic voltammograms recorded at rGO-SPCE in BR buffer ( $\mathrm{pH} 7.0$ ) containing: (A) $0.5 \mathrm{mM}$ UA; (B) $5.0 \mathrm{mM} \mathrm{AA}$; and (C) $0.5 \mathrm{mM} \mathrm{DA}$, at scan rates of: (a) 10; (b) 50; (c) 100; (d) 150; and (e) $200 \mathrm{mV} \cdot \mathrm{s}^{-1}$. Inserts: $I_{\text {pa }}$ vs. $\sqrt{ } v$.

\subsection{The Effect of $\mathrm{pH}$ on Voltammetric Behavior of $U A, A A$ and $D A$ at $r G O-S P C E$}

The effect of $\mathrm{pH}$ on $I_{\mathrm{pa}}$ and $E_{\mathrm{pa}}$ were also examined in the range of 3.0-10.0. As shown in Figure $4 \mathrm{~A}$, when the $\mathrm{pH}$ of the solution was increased, $I_{\mathrm{pa}}$ increased gradually and then decayed with the optimum $\mathrm{pH}$ being 7.0. Moreover, considering the fact that physiological $\mathrm{pH}$ is around 7.0 [26], BR buffer solution of $\mathrm{pH} 7.0$ was used as the supporting electrolyte for the analyses of the compounds. Figure $4 \mathrm{~B}$ illustrates the effect of $\mathrm{pH}$ on $E_{\mathrm{pa}}$, which followed the linear regression equations $\operatorname{Ep} a(V)=0.51-0.06 p H, \mathrm{R}^{2}=0.9998$ for $\mathrm{UA}, \mathrm{E} p a(V)=0.45-0.04 p H, \mathrm{R}^{2}=0.9996$ for $\mathrm{AA}$, and $\mathrm{E} p a(V)=0.72-0.06 p H, \mathrm{R}^{2}=0.9995$ for DA. The $E_{\mathrm{pa}}$ shifted with every increase of the $\mathrm{pH}$ value of the supporting electrolyte for all the three compounds, suggesting that the reactions at rGO-SPCE were accompanied by proton transfers [27]. The slope values of $60.0 \mathrm{mV} \cdot \mathrm{pH}^{-1}$ for both $\mathrm{UA}$ and DA suggest that their electrocatalytic reactions involved the transfer of equal number of protons and electrons [28]. However, the slope value of $40.0 \mathrm{mV} \cdot \mathrm{pH}^{-1}$ for AA is similar to the value given by the Nernstian equation for reactions involving unequal electron and proton transfers [29]; thus, the overall reaction of AA at rGO-SPCE could be classified as an electrochemical process that is followed by a chemical reaction [30]. 

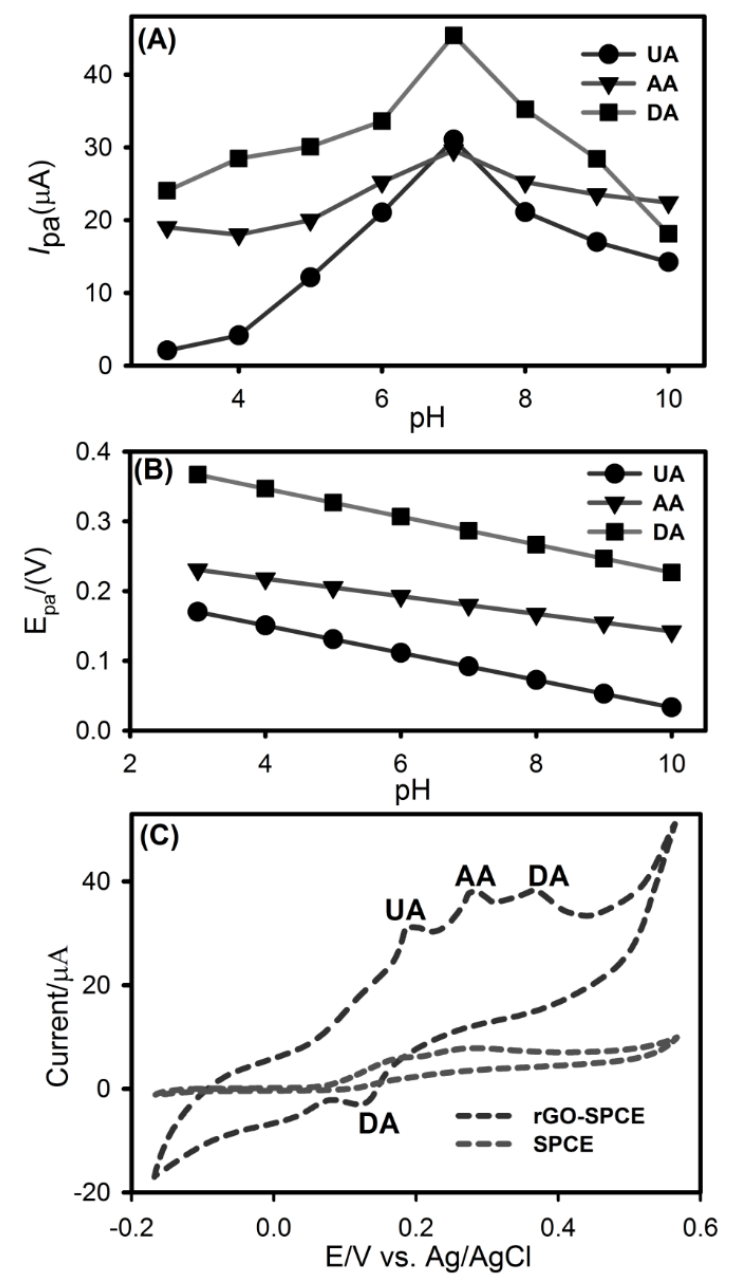

Figure 4. Effect of $\mathrm{pH}$ on the: (A) $I_{\mathrm{pa}}$; and (B) $E_{\mathrm{pa}}$ of UA $(0.5 \mathrm{mM}), \mathrm{AA}(5.0 \mathrm{mM})$ and DA $(0.5 \mathrm{mM})$ at rGO-SPCE. (C) Cyclic voltammograms of ternary mixture of UA (0.5 mM), AA (5.0 mM) and DA $(0.5 \mathrm{mM})$ at SPCE and rGO-SPCE. Supporting electrolyte was BR buffer ( $\mathrm{pH} 7.0), 50 \mathrm{mV} \cdot \mathrm{s}^{-1} \mathrm{scan}$ rate.

\subsection{Analysis of Ternary Mixture of UA, AA and DA at SPCE and rGO-SPCE}

The electrochemical behaviour of a ternary mixture of UA, AA and DA at SPCE and rGO-SPCE was evaluated by $\mathrm{CV}$ in order to further understand the electrochemical properties of the electrodes. At the SPCE, shown in Figure 4C, only two slightly overlapping anodic peaks were obtained at $\sim 0.18$ and $\sim 0.287 \mathrm{~V}$; thus, the $E_{\mathrm{pa}}$ for $\mathrm{UA}, \mathrm{AA}$ and DA were indistinguishable, indicating poor selectivity and sensitivity. In contrast, three well-resolved $E_{\text {pa }}$ were observed at 0.183 (for UA), 0.273 (for AA) and $0.317 \mathrm{~V}$ (for DA) on rGO-SPCE. The $\Delta E_{\mathrm{p}}$ for UA-AA and AA-DA were $90 \mathrm{mV}$ and $44 \mathrm{mV}$, respectively, which is large enough to allow for simultaneous analysis of the compounds in their ternary mixtures.

\subsection{DPV Analysis of Ternary Mixtures of $U A, A A$ and $D A$ at $r G O-S P C E$}

Differential pulse voltammetry (DPV), a widely utilized analytical method for the enhancement of electrode specificity and sensitivity [30], was carried out by varying the concentration of one of the compounds while the concentrations of the other two remained constant. As shown in Figure $5 \mathrm{~A}-\mathrm{C}$, the $I_{\mathrm{pa}}$ for the three molecules increased linearly with increasing concentrations, suggesting a stable and efficient electrocatalytic activity at the rGO-SPCE. For UA detection, $2.5 \mathrm{mM}$ $\mathrm{AA}$ and $50.0 \mu \mathrm{M}$ DA are mixed in BR buffer $(\mathrm{pH} 7.0)$ and the corresponding linear regression equation is defined as $\operatorname{Ipa}(\mu A)=0.03[U A](\mu M)+23.09, R^{2}=0.9998([U A]=10 \mu M-3000 \mu M)$. For AA detection, $250.0 \mu \mathrm{M}$ UA and $50.0 \mu \mathrm{M}$ DA are mixed in BR buffer (pH 7.0) and the 
corresponding linear regression equation is defined as $\operatorname{Ipa}(\mu A)=12.90[A A](m M)+8.55$, $R^{2}=0.9996([A A]=0.1 m M-2.5 m M), \operatorname{Ipa}(\mu A)=2.02[A A](m M)+56.51, R=0.9985$ $([A A]=5.0 m M-20 m M)$.

For DA detection, $250.0 \mu \mathrm{M}$ UA and $2.5 \mathrm{mM}$ AA are mixed in BR buffer $(\mathrm{pH} 7.0)$ and the corresponding linear regression equation is defined as $\operatorname{Ipa}(\mu A)=0.97[D A](\mu M)+$ 2.26, $R=0.9984([D A]=0.20 \mu M-80.00 \mu M)$, Ipa $(\mu A)=0.13[D A](m M)+75.56, R=$ $0.9975([D A]=120.0 \mu M-500 \mu M)$. The calculated limits of detection $(\mathrm{S} / \mathrm{N}=3)$ for UA, AA and DA were found to be $0.4 \mu \mathrm{M}, 50.0 \mu \mathrm{M}$ and $0.1 \mu \mathrm{M}$, respectively. These linear ranges and detection limits are better than some of the results obtained from the analysis of the compounds using similar modified electrodes (Table 2) and were deemed to be satisfactory for routine analysis of UA, AA and DA.
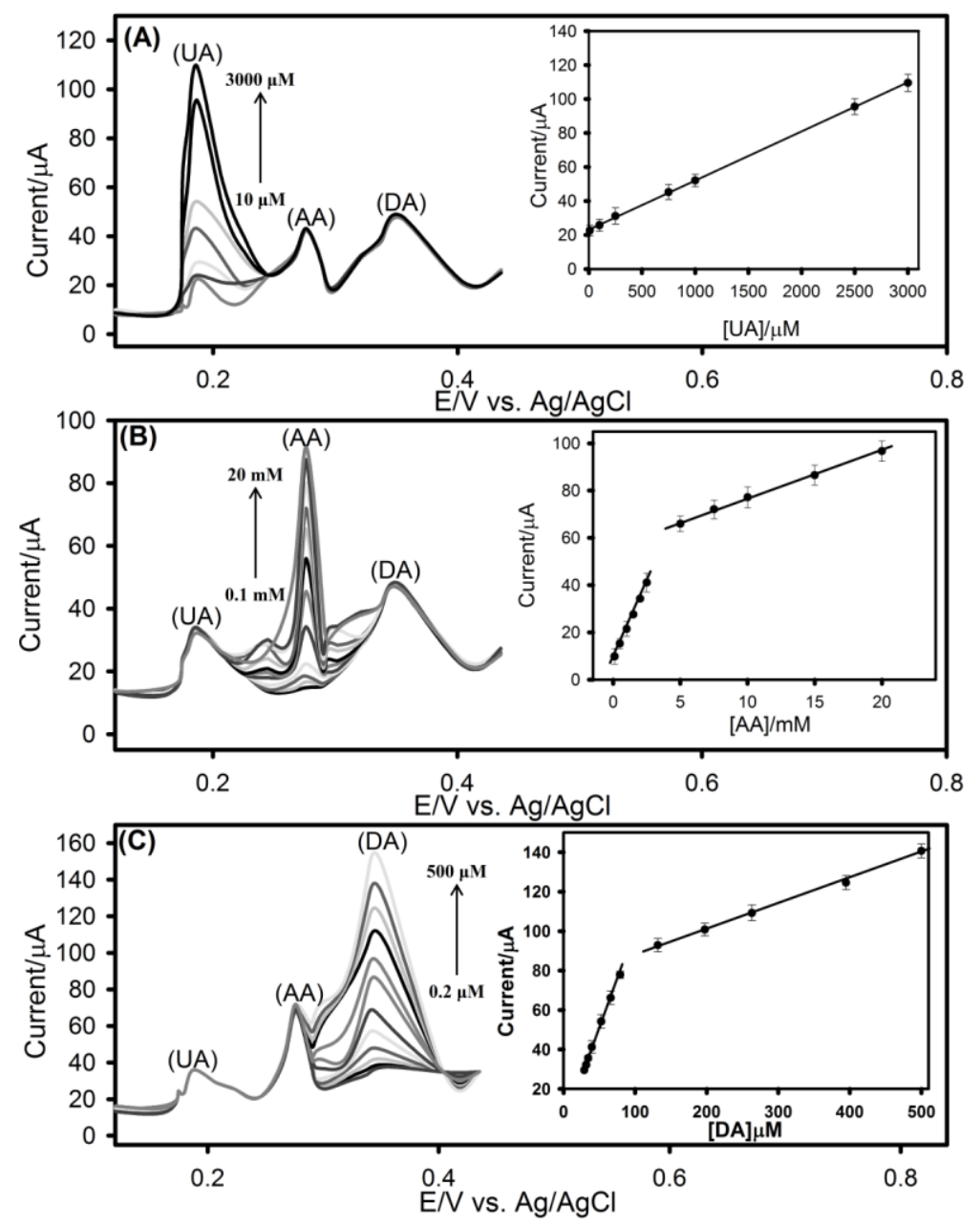

Figure 5. DPVs of UA, AA and DA at rGO-SPCE in BR buffer ( $\mathrm{pH} 7.0), 50 \mathrm{mV} \cdot \mathrm{s}^{-1}$ scan rate: (A) UA concentrations of $10.0,100.0,250.0,750.0,1000.0,2500.0$ and $3000.0 \mu \mathrm{M}$ in the presence of $2.5 \mathrm{mM} \mathrm{AA}$ and $50.0 \mu \mathrm{M}$ DA; (B) AA concentrations of $0.1,0.5,1.0,1.5,2.0,2.5,5,7.5,10.0,15.0$, and $20.0 \mathrm{mM}$ in the presence of $250.0 \mu \mathrm{M}$ UA and $50.0 \mu \mathrm{M} \mathrm{DA}$; and (C) DA concentrations of $0.2,20.0,30.0,40.0,50.0,70.0$, $80.0,120.0,200.0,250.0,400.0$ and $500.0 \mu \mathrm{M}$ in the presence of $250.0 \mu \mathrm{M}$ UA and $2.5 \mathrm{mM}$ AA. Inserts: $I_{\mathrm{p}}$ vs. concentration. 
Table 2. Comparison of the analytical performance characteristics of UA, AA and DA electrodes.

\begin{tabular}{|c|c|c|c|c|c|c|c|}
\hline \multirow[t]{2}{*}{ Electrode Material } & \multicolumn{3}{|c|}{ Limit of Detection $(\mu \mathrm{M})$} & \multicolumn{3}{|c|}{ Linear Range $(\mu \mathrm{M})$} & \multirow[t]{2}{*}{ Reference } \\
\hline & UA & AA & DA & UA & AA & DA & \\
\hline ERGO-GCE & 0.5 & 300.0 & 0.5 & $0.5-60.0$ & $500.0-2000.0$ & $0.5-60.0$ & [31] \\
\hline GCE & 4.7 & 23.38 & 2.67 & $5.0-70.0$ & $25,000.0-300,000.0$ & $3.0-30.0$ & [32] \\
\hline Trp-GR & 1.24 & 10.09 & 0.29 & $10.0-1000.0$ & $\begin{array}{c}200.0-3400.0 \\
3400.0-12,900.0\end{array}$ & $0.5-110.0$ & [33] \\
\hline PdNPs-GR-CS-GCE & 0.17 & 20.0 & 0.1 & $0.5 .0-200.0$ & $100.0-400.0$ & $\begin{array}{c}0.50-15.0 \\
20.00-200.00\end{array}$ & [34] \\
\hline AgNPs-rGO-GCE & 8.2 & 9.6 & 5.4 & $10.0-800.0$ & $10.0-800.0$ & $10.00-800.00$ & [35] \\
\hline MWCNT-GCE & 0.42 & 7.71 & 0.31 & $0.55-90.0$ & $15.0-800.0$ & $0.50-100.00$ & [36] \\
\hline Nitrogen doped GR & 0.045 & 2.2 & 0.25 & $0.1-20.0$ & $5.0-1300.0$ & $0.50-170.00$ & [29] \\
\hline poly(Tyr)-MWCNTs-COOH-GCE & 0.3 & 2.0 & 0.02 & $1.0-350.0$ & $50-1000.0$ & $0.10-30.00$ & [37] \\
\hline Screen printed graphene electrode & 0.2 & 0.95 & 0.12 & $0.8-2500.0$ & $4.0-4500.0$ & $0.50-2000.00$ & [38] \\
\hline HCNTs-GCE & 1.5 & 0.92 & 0.8 & $6.7-65.0$ & $7.5-180.0$ & $2.50-105.00$ & [39] \\
\hline IL-GR-GCE & 0.323 & - & 0.679 & $1.0-600.0$ & - & $1.00-400.00$ & {$[40]$} \\
\hline rGO-SPCE & 0.35 & 50 & 0.1 & $10.0-3000.0$ & $\begin{array}{c}\text { 100.0-2500.0 } \\
5000.0-20000.0\end{array}$ & $\begin{array}{l}0.20-80.00 \\
120.0-500.0\end{array}$ & This study \\
\hline
\end{tabular}




\subsection{Reproducibility and Stability of rGO-SPCE, and Ternary Mixture Analysis}

In order to evaluate the reproducibility of rGO-SPCE, a single rGO-SPCE was used $(n=6)$ to determine the concentrations of the compounds in a ternary mixture $(250.0 \mu \mathrm{M} \mathrm{UA}, 2.5 \mathrm{mM} \mathrm{AA}$, and $50.0 \mu \mathrm{M} \mathrm{DA}$ ) by DPV. It was found that the relative standard deviations for the peak current intensities for UA, AA and DA were $1.05 \%, 1.51 \%$ and $1.25 \%$, respectively. The stability of rGO-SPCE was also determined in a similar fashion after storage in room temperature for 21 days; the peak current intensities for UA, AA and DA decayed by less than $2.5 \%$, suggesting that the electrodes were highly stable over the 21-day period. The rGO-SPCE was also used to analyse ternary mixtures of the compounds in urine using standard addition method. The analytical performance data are summarized in Table 3. The recoveries were in the range of $98.07 \%$ to $99.97 \%$ with a relative standard deviation (RSD, $\mathrm{n}=3$ ) of less than $1.5 \%$. Clearly, the presence of common interferences in the urine samples did not interfere with the analysis of the compounds; thus, the sensor can be used for routine simultaneous quantification of the compounds in biological samples.

Table 3. Recovery of UA, AA and DA from ternary mixtures in urine.

\begin{tabular}{cccc}
\hline Sample & Amount Added $(\mu \mathbf{M})$ & Amount Recovered $(\mu \mathrm{M})$ & Mean Recovery $(\%)$ \\
\hline UA & - & - & - \\
\hline Repeat 1 & 50 & 47.9 & \\
Repeat 2 & 50 & 49.4 & \\
Repeat 3 & 50 & 49.8 & 98.07 \\
Mean & - & 49.033 & - \\
\hline AA & - & - & \\
\hline Repeat 1 & 500 & 497.3 & \\
Repeat 2 & 500 & 499.7 & - \\
Repeat 3 & 500 & 499.5 & \\
Mean & - & 499.833 & \\
\hline DA & & - & \\
\hline Repeat 1 & 50 & 49.4 & \\
Repeat 2 & 50 & 48.8 & \\
Repeat 3 & 50 & 49.9 & \\
Mean & - & 49.367 & \\
\hline
\end{tabular}

\section{Conclusions}

An in-house fabricated screen-printed carbon electrode, modified with chemically reduced graphene oxide, has been demonstrated as a useful analytical sensing tool for simultaneous analysis of uric acid, ascorbic acid and dopamine. The sensor showed stable responses for repeated measurements and good electrocatalytic capability that enabled the resolution of three voltammetric peaks associated with the compounds, thus enabling their simultaneous analyses. The sensor could be employed for routine simultaneous analysis of $\mathrm{UA}, \mathrm{AA}$ and DA.

Acknowledgments: The authors would like to thank the Department of Employment and Learning Ireland (Grant No.: USI035) and the National Institutes of Health (Grant No.: 5R01ES003154-30) for the funding.

Author Contributions: Prosper Kanyong conceived, designed and performed the experiments, analyzed the data, and wrote the paper. Sean Rawlinson designed and printed the electrodes. James Davis provided reagents, materials and equipment, and supervised the project.

Conflicts of Interest: The authors declare no conflict of interest.

\section{References}

1. Ruggiero, C.; Cherubini, A.; Ble, A.; Bos, J.G.A.; Magio, M.; Dixit, D.V.; Lauretani, F.; Bandinelli, S.; Senin, U.; Ferrucci, L. Uric acid and inflammatory markers. Eur. Heart J. 2006, 27, 1174-1181. [CrossRef] [PubMed]

2. Riches, P.L.; Wright, A.F.; Ralston, S.H. Recent insights into the pathogenesis of hyperuricemia and gout. Hum. Mol. Genet. 2009, 18, R177-R184. [CrossRef] [PubMed] 
3. Davey, M.W.; van Montagu, M.; Inze, D.; Sanmartin, M.; Kanellis, A.; Smirnoff, N.; Benzie, I.J.J.; Strain, J.J.; Favel, D.; Fletcher, J. Plant L-ascorbic acid: Chemistry, function, metabolism, bioavailability and effects of processing. J. Sci. Food Agric. 2005, 80, 825-860. [CrossRef]

4. Englard, S.; Seifter, S. The biochemical functions of ascorbic acid. Annu. Rev. Nutr. 1986, 6, $365-406$. [CrossRef] [PubMed]

5. Kurian, M.A.; Gissen, P.; Smith, M.; Heales, S.J.; Clayton, P.T. The monoamine neurotransmitter disorders: An expanding range of neurological syndromes. Lancet Neurol. 2011, 10, 721-733. [CrossRef]

6. Schultz, W. Multiple dopamine functions at different time courses. Annu. Rev. Neurosci. 2007, 30, $259-288$. [CrossRef] [PubMed]

7. Gowrishankar, R.; Hahn, M.K.; Blakely, R.D. Good riddance to dopamine: Roles for the dopamine transporter in synaptic function and dopamine-associated brain disorders. Neurochem. Int. 2014, 73, 42-48. [CrossRef] [PubMed]

8. Camardese, G.; Giuda, D.; Nicola, M.; Cocciolillo, F.; Giordano, A.; Janiri, L.; Guglielmo, R. Imaging studies on dopamine transporter and depression: A review of literature and suggestions for future research. J. Psychiatr. Res. 2014, 51, 7-18. [CrossRef] [PubMed]

9. Szantai, E.; Szilagyi, A.; Guttman, A.; Sasvari-Szekely, M.; Ronai, Z. Genotyping and hapotyping of the dopamine D4 receptor gene by capillary electrophoresis. J. Chromatogr. A 2004, 1053, 241-245. [CrossRef] [PubMed]

10. Sajid, M.S.; Nazal, M.K.; Mansha, M.; Alsharaa, A.; Jillani, S.M.S.; Basheer, C. Chemically modified electrodes for electrochemical detection of dopamine in the presence of uric acid and ascorbic acid: A review. TrAc Trends Anal. Chem. 2016, 76, 15-29. [CrossRef]

11. González, R.R.; Fernández, R.F.; Vidal, J.L.M.; Frenich, A.G.; Pérez, M.L.G. Development and validation of an ultra-high performance liquid chromatography-tandem mass-spectrometry (UHPLC-MS/MS) method for the simultaneous determination of neurotransmitters in rat brain samples. J. Neurosci. Methods 2011, 198, 187-194. [CrossRef] [PubMed]

12. Gao, Z.Q.; Huang, H. Simultaneous determination of dopamine, uric acid and ascorbic acid at an ultrathin film modified gold electrode. Chem. Commun. 1998, 19, 2107-2108. [CrossRef]

13. Welch, C.W.; Compton, R.G. The use of nanoparticles in electroanalysis: A review. Anal. Bioanal. Chem. 2006, 384, 601-619. [CrossRef] [PubMed]

14. Safavi, A.; Maleki, N.; Moradlou, M.; Tajabadi, F. Simultaneous determination of dopamine, ascorbic acid and uric acid using carbon ionic liquid electrode. Anal. Biochem. 2006, 359, 224-229. [CrossRef] [PubMed]

15. Ensafi, A.A.; Taei, M.; Khayamian, T. Simultaneous determination of ascorbic acid, dopamine and uric acid by differential pulse voltammetry using tiron modified glassy carbon electrode. Int. J. Electrochem. Sci. 2010, 5, 116-130.

16. Kalimuthu, P.; John, S.A. Simultaneous determination of ascorbic acid, dopamine, uric acid and xanthine using a nanostructured polymer film modified electrode. Talanta 2010, 80, 1686-1691. [CrossRef] [PubMed]

17. Shakkthivel, P.; Chen, S. Simultaneous determination of ascorbic acid and dopamine in the presence of uric acid on ruthenium oxide modified electrode. Biosens. Bioelectron. 2007, 22, 1680-1687. [CrossRef] [PubMed]

18. Cinti, S.; Ardunini, F.; Carbone, M.; Sansone, L.; Cacciotti, I.; Moscone, D.; Palleschi, G. Screen-printed electrodes modified with carbon nanomaterials: A comparison among carbon black, carbon nanotubes and graphene. Electroanalysis 2015, 27, 2230-2238. [CrossRef]

19. Chua, C.K.; Pumera, M. Reduction of graphene oxide with substituted borohydrides. J. Mater. Chem. A 2013, 1, 1892-1898. [CrossRef]

20. Kanyong, P.; Rawlinson, S.; Davis, J. Gold nanoparticle modified screen-printed carbon arrays for the simultaneous electrochemical analysis of lead and copper in tap water. Microchim. Acta 2016, 183, 2361-2368. [CrossRef]

21. Kanyong, P.; Rawlinson, S.; Davis, J. Fabrication and electrochemical characterization of polydopamine redox polymer modified screen-printed carbon electrode for the detection of guanine. Sens. Actuators B Chem. 2016, 233, 528-534. [CrossRef]

22. Paredes, J.I.; Villar-Rodil, S.; Martinez-Alonso, A.; Tascon, J.M.D. Graphene oxide dispersions in organic solvents. Langmuir 2008, 24, 10560-10564. [CrossRef] [PubMed]

23. Li, D.; Muller, M.B.; Gilje, S.; Kaner, R.B.; Wallace, G.G. Processable aqueous dispersions of graphene nanosheets. Nat. Nanotechnol. 2008, 3, 101-105. [CrossRef] [PubMed] 
24. Suni, I.I. Impedance methods for electrochemical sensors using nanomaterials. Trends Anal. Chem. 2008, 27, 604-611. [CrossRef]

25. Ponnusamy, V.K.; Mani, V.; Chen, S.M.; Huang, W.T.; Jen, J.F. Rapid microwave assisted synthesis of graphene nanosheets/polyethylenimine/gold nanoparticle composite and its application to the selective electrochemical determination of dopamine. Talanta 2014, 120, 140-157. [CrossRef] [PubMed]

26. Temocin, Z. Modification of glassy carbon electrode in basic medium by electrochemical treatment for simultaneous determination of dopamine, ascorbic acid and uric acid. Sens. Actuators B Chem. 2013, 176, 796-802. [CrossRef]

27. Habibi, B.; Pournaghi-Azar, M.H. Simultaneous determination of ascorbic acid, dopamine and uric acid by use of a MWCNT modified carbon-ceramic electrode and differential pulse voltammetry. Electrochim. Acta 2010, 55, 5492-5498. [CrossRef]

28. Komura, T.; Niu, G.Y.; Yamaguchi, T.; Asano, M.; Matsuda, A. Coupled electron-proton transport in electropolymerized methylene blue and the influences of its protonation level on the rate of electron exchange with nicotinamide adenine dinucleotide. Electroanalysis 2010, 16, 1791-1800. [CrossRef]

29. Sheng, Z.H.; Zheng, X.Q.; Xu, J.Y.; Bao, W.J.; Wang, F.B.; Xia, X.H. Electrochemical sensor based on nitrogen doped graphene: Simultaneous determination of ascorbic acid, dopamine and uric acid. Biosens. Bioelectron. 2012, 34, 125-131. [CrossRef] [PubMed]

30. Evans, D.H. Review of voltammetric methods for the study of electrode reactions. In Microelectrdodes: Theory and Applications; Montenegro, M.R.M., Quirós, A., Daschbach, J.L., Eds.; Springer: Rotterdam, The Netherlands, 1991; pp. 17-32.

31. Yang, L.; Liu, D.; Huang, J.S.; You, T.Y. Simultaneous determination of dopamine, ascorbic acid and uric acid at electrochemically reduced graphene oxide modified electrode. Sens. Actuators B Chem. 2014, 193, 166-172. [CrossRef]

32. Wang, Y.; Tong, L.L. Electrochemical sensor for simultaneous determination of uric acid, xanthine, and hypoxanthine based on poly (bromocresol purple) modified glassy carbon electrode. Sens. Actuators B Chem. 2010, 150, 43-49. [CrossRef]

33. Lian, Q.; He, Z.; He, Q.; Luo, A.; Yan, K.; Zhang, D.; Lu, X.; Zhou, X. Simultaneous determination of ascorbic acid, dopamine and uric acid based on trptophan functionalized graphene. Anal. Chim. Acta 2014, 823, 32-39. [CrossRef] [PubMed]

34. Zhang, F.Y.; Wang, Z.H.; Zhang, Y.Z.; Zheng, Z.X.; Wang, C.M.; Du, Y.L.; Ye, W.C. Simultaneous electrochemical determination of uric acid, xanthine and hypoxanthine based on poly(L-arginine)/graphene composite film modified electrode. Talanta 2012, 93, 20-325. [CrossRef] [PubMed]

35. Kaur, B.; Panidyan, T.; Satpati, B.; Srivastava, R. Simultaneous and sensitive determination of ascorbic acid, dopamine, uric acid and tryptophan with silver nanoparticles-decorated reduced graphene oxide modified electrode. Colloid. Surface B 2013, 11, 97-106. [CrossRef] [PubMed]

36. Wang, X.; Wu, M.; Tang, W.R.; Zhu, Y.; Wang, L.W.; Wang, Q.J.; He, P.G.; Fang, Y.Z. Simultaneous electrochemical determination of ascorbic acid, dopamine and uric acid suing a palladium nanoparticles/graphene/chitosan modified electrode. J. Electroanal. Chem. 2013, 695, 10-16. [CrossRef]

37. Li, S.J.; Qian, C.; Wang, K.; Hua, B.Y.; Wang, F.B.; Sheng, Z.H.; Xia, X.H. Application of thermally reduced graphene oxide modified electrode in simultaneous determination of dihydroxybenzene isomers. Sens. Actuators B Chem. 2012, 174, 441-448. [CrossRef]

38. Ping, J.F.; Wang, J.W.Y.X.; Ying, Y.B. Simultaneous determination of ascorbic acid, dopamine and uric acid using high-performance screen-printed graphene electrode. Biosens. Bioelectron. 2012, 34, 70-76. [CrossRef] [PubMed]

39. Cui, R.J.; Wang, X.Y.; Zhang, G.H.; Wang, C. Simultaneous determination of dopamine, ascorbic acid and uric acid using helical carbon nanotubes modified electrode. Sens. Actuators B Chem. 2012, 161, 1139-1143. [CrossRef]

40. Wang, C.F.; Xu, P.P.; Zhuo, K.L. Ionic liquid functionalized graphene-based electrochemical biosensor for simultaneous determination of dopamine and uric acid in the presence of ascorbic acid. Electroanalysis 2014, 26, 191-198. [CrossRef]

(C) 2016 by the authors; licensee MDPI, Basel, Switzerland. This article is an open access article distributed under the terms and conditions of the Creative Commons Attribution (CC-BY) license (http://creativecommons.org/licenses/by/4.0/). 